\title{
The prevalence of human immunodeficiency virus infection among TB patients in Port Harcourt Nigeria
}

This article was published in the following Dove Press journal:

HIVIAIDS - Research and Palliative Care

13 January 2010

Number of times this article has been viewed

O Erhabor'

Z A Jeremiah ${ }^{2}$

T C Adias'

Okere $C E^{2}$

'Department of Medical Laboratory Sciences, College of Health Sciences, Niger Delta University, Wilbeforce

Island, Bayelsa State, Nigeria;

${ }^{2}$ Department of Medical Laboratory

Sciences, Rivers State University

of Science and Technology, Port

Harcourt, Nigeria
Correspondence: Osaro Erhabor Blood Sciences Department, Royal Bolton Hospital NHS Trust, Bolton UK

Email n_osaro@yahoo.com

\begin{abstract}
The joint statement by the American Thoracic Society, Centers for Disease Control and Prevention, and Infectious Diseases Society of America recommends that all patients with tuberculosis (TB) undergo testing for human immunodeficiency virus (HIV) infection after counseling. In this study, we investigated the prevalence of HIV infection among 120 patients diagnosed with microbiologically proven TB aged 18 to 54 years with a mean age of 39.5 years (standard deviation 6.75). The subjects studied were 36 male (30\%) and 84 females $(70 \%)$. Enzyme-linked immunosorbent assay methods were used to screen for HIV infection among the subjects. Of the $120 \mathrm{~TB}$ patients tested $30(25 \%)$ were positive for HIV infection. The prevalence of HIV was higher in females $24(80 \%)$ compared to males $6(20 \%)$ and among singles $(66.7 \%)$ compared to married subjects (33.3\%) $\left(\chi^{2}=83.5\right.$ and $\chi^{2}=126.2$, respectively $P=0.001)$. HIV-1 was the predominant viral subtype. HIV prevalence was significantly higher in subjects in the 38-47 year and 28-37 year age groups (both $40 \%$ ) followed by the 18-28 year age group $(20 \%)\left(\chi^{2}=42.6, P=0.05\right)$. The mean CD4 lymphocyte count of the HIV-infected TB subjects was significantly lower $(195 \pm 40.5$ cells $/ \mu \mathrm{L})$ compared to the non-HIV infected ( $288 \pm 35.25$ cells $/ \mu \mathrm{L} P=0.01)$. This study has shown a high prevalence of HIV among TB patients. Reactivation of TB among people living with HIV can be reduced by TB preventive therapy and by universal access to antiretroviral therapy.
\end{abstract}

Keywords: human immunodeficiency virus, HIV, acquired immunodeficiency syndrome AIDS, tuberculosis, TB, Port Harcourt, Nigeria

\section{Introduction}

Tuberculosis (TB) and human immunodeficiency virus (HIV) have been closely linked since the emergence of acquired immunodeficiency syndrome (AIDS). HIV infection has contributed to a significant increase in the worldwide incidence of TB. ${ }^{1,2}$ By producing a progressive decline in cell-mediated immunity, HIV alters the pathogenesis of TB, greatly increasing the risk of developing the disease in co-infected individuals, leading to more frequent extrapulmonary involvement and atypical radiographic manifestations. Although HIV-related TB is treatable and preventable, incidence rates continue to climb in developing nations where HIV infection and TB are endemic and resources are limited. Worldwide, TB is the most common opportunistic infection affecting HIV seropositive individuals, ${ }^{1}$ and it is the most common cause of death in patients with AIDS. ${ }^{3}$ The prevalence of HIV infection among TB patients in several African countries ranges from $20 \%$ to $60 \% .{ }^{1}$ The World Health Organization (WHO) estimates that about 8 million new cases of TB and nearly 2 million deaths from the disease occur each year. ${ }^{4}$ Approximately 10 million people are estimated submit your manuscript $\mid$ www.dovepress.com

Dovepress 
to be coinfected with TB and HIV, and over $90 \%$ of these dually infected individuals reside in developing nations. In some areas of sub-Saharan Africa, the rates of coinfection exceed 1,000 per 100,000 populations. ${ }^{5}$ Worldwide, a similar change has occurred in some developed countries. The HIV epidemic has increased the global TB burden and focused attention on the need to strengthen links between TB and HIV/AIDS program. In response to these health emergencies, the WHO has developed an expanded strategy aimed at reducing the burden of HIV-related TB infection through close collaboration between TB and HIV/AIDS programmes. Infection with HIV is the most well known risk factor for the development of TB. Because of the prevalence of TB amongst HIV-infected patients the joint statement by the American Thoracic Society, Centers for Disease Control and Prevention, and Infectious Diseases Society of America recommends that all patients with $\mathrm{TB}$ undergo testing for HIV infection after counseling. ${ }^{6,7}$ The aim of this study was to evaluate the prevalence of retroviral infection among TB infected and previously undiagnosed HIV patients in Port Harcourt Nigeria.

\section{Material and methods}

\section{Subjects}

A total of 120 patients with microbiologically confirmed pulmonary TB attending the Niger hospital chest clinic (situated in Diobu, Port Harcourt, Nigeria) were consecutively recruited for this study between July and August 2006. The diagnosis of TB in the chest clinic is based on patients providing 3 sputum specimens on 3 consecutive days, examined for acid fast bacilli (AFB) and cultured for mycobacterium. Culture of mycobacterium is a much more sensitive test than smear examination and has been estimated to detect $10-100$ viable microbacteria per $\mathrm{mL}$ of sample, and in cases of active disease they are found to be $81 \%$ sensitive and $98.5 \%$ specific. $^{8}$ Inclusion criteria included microbiological confirmation of pulmonary $\mathrm{TB}$, age $\geq 18$ years. Written informed consent was obtained from all study subjects. Pre- and post- test counseling was offered to all test subjects. Subjects were made up of 36 men and 84 women with age range 18-54 years and mean age of 39.5 years (standard deviation 6.75). Ethical approval was obtained from the Department of Medical Laboratory Science, University of Science and Technology Institutional Review Board, (Port Harcourt).

\section{Sample collection/preparation}

Six mL of venous blood was collected from each patient. Three $\mathrm{mL}$ were poured into a sterile gel tube without anti-coagulant and $3 \mathrm{~mL}$ into a second EDTA anticoagulated tube. The blood in the gel tubes was allowed to clot, after which it was centrifuged for 10 minutes to separate the serum from the clotted cells. Sera from all patients were then screened for the presence of HIV antibodies: using the WHO recommended strategy for HIV antibody testing using two kit methods. The HIV screening was undertaken using the Abbott Determine HIV 1 an enzyme linked immunosorbent assay (ELISA) test (Abbott Diagnostics, Tokyo, Japan). The test is an immuno-chromatographic test for the qualitative and differential diagnosis of HIV 1 and 2 in human serum. All initially positive tests were confirmed using Immunocomb HIV 1 and 2 kits (Orgenics, Yavne, Israel). CD4 lymphocyte count was carried out on the EDTA anticoagulated sample using the Dynal beads method (Invitrogen, Carlsbad, CA). This method is an alternative method to flow cytometry for the enumeration of peripheral CD4 lymphocyte in resource-limited settings. The Dynal beads technique uses paramagnetic polymer beads coated with anti CD4 monoclonal antibodies (mAbs) to capture and isolate CD4 T-lymphocyte from whole blood. Previous study indicated that CD4 count from Dynal beads method correlated positively and significantly with values from flow cytometry $(\mathrm{r}=0.90){ }^{9}{ }^{9}$

\section{Statistical analysis}

Data was analyzed using a Statistical Package for Social Sciences version 10 (SPSS Inc, Chicago IL USA). Results was expressed as mean and standard deviation. Differences in prevalence of HIV for demographics (age, sex and marital status) variables among TB-infected subjects were tested for significance by chi square analysis. A $P$-value of $<0.05$ was considered significant in all statistical comparisons.

\section{Results}

Of the $120 \mathrm{~TB}$ patient tested for HIV, 30 (25\%) were positive. HIV prevalence was higher in females $24(80 \%)$ when compared to males $6(20 \%)$ as well as among singles $(66.7 \%)$ as compared to married patients $(33.3 \%)$ $\left(\chi^{2}=83.5\right.$ and $\chi^{2}=126.2$ respectively $\left.P=0.001\right)$. HIV prevalence was significantly higher in subjects in the 38-47 and 28-37 years age groups (both 40\%) followed by the $18-28$ years age group $(20 \%)\left(\chi^{2}=42.6, P=0.04\right)$. The mean CD4 lymphocyte count of the HIV-infected subjects was significantly lower $(P=0.001)(195 \pm 40.5$ cells $/ \mu \mathrm{L})$ compared to the non-HIV-infected $(288 \pm 35.25$ cells $/ \mu \mathrm{L})$. HIV 1 was the predominant viral subtype. Table 1 shows the distribution of HIV serological prevalence among TB infected patients based on age, gender and marital status. 
Table I Distribution of HIV serological prevalence among TB patients based on age, gender and marital status

\begin{tabular}{lllll}
\hline Variable & $\begin{array}{l}\text { Number } \\
\text { tested }\end{array}$ & $\begin{array}{l}\text { Number (\%) } \\
\text { HIV positive }\end{array}$ & $\chi^{2}$ & P-value \\
\hline Age (years) & & $6(20)$ & 42.6 & 0.04 \\
$18-27$ & 54 & $12(40)$ & & \\
$28-37$ & 48 & $12(40)$ & & \\
$38-47$ & 12 & $0(0)$ & & \\
$48-57$ & 6 & $6(20)$ & 83.5 & 0.001 \\
Gender & & $24(80)$ & & \\
Male & 36 & & & \\
Female & 84 & $10(33.6)$ & 126.2 & 0.001 \\
Marital status & $20(66.7)$ & & \\
Married & 78 & 42 &
\end{tabular}

\section{Discussion}

There is variable information concerning the prevalence of HIV among TB-infected patients in the Nigerian population. In this study we observed a $25 \%$ HIV prevalence among adult TB patients. This finding is in agreement with previous reports in Nguru in the North eastern Nigeria. ${ }^{10}$ Similarly out of 59 patients with pulmonary TB studied in Kampala, Uganda, ${ }^{11}$ two-thirds of the patients were HIVseropositive. Similarly in Sagamu, Nigeria Daniel and colleagues $^{12}$ observed a $14.9 \%$ HIV prevalence amongst their cohort of TB infected patients. Of patients with confirmed pulmonary TB in Zambia, 49\% were positive for HIV. ${ }^{13}$ Studies among TB patients in Kenya ${ }^{14}$ observed $40.7 \%$ prevalence while nearly $40 \%$ of the smear-positive TB patients in Tanzania were attributable to HIV. ${ }^{15}$ However, out of 13,269 patients diagnosed with TB in the Netherlands who were then tested for HIV between 1993 to 2001, 542 were HIV positive (4.1\%). ${ }^{16}$ Among 184 newly diagnosed TB patients tested for HIV in Singapore, 15 (8.2\%) was seropositive. ${ }^{6}$

For many years; the efforts to tackle TB and HIV have been largely separate, despite the overlapping epidemiology. However, it is now increasingly recognized that only through combined and coordinated efforts for both TB and HIV can this dual epidemic be halted. There is an increasingly alarming trend in the overall incidence of TB across the globe. While several regions seem to be experiencing declines in TB incidence, there is a dramatic increase in Africa. HIV-positive individuals are at greater risk of contracting such opportunistic infections such as TB, and treatment for co-infected patients is complicated by interactions between prescribed drugs. Furthermore, TB control efforts have been hampered in countries that are overwhelmed by the HIV/AIDS epidemic.

The mean CD4 lymphocyte count of the HIV-infected TB subjects was significantly lower $(P=0.01)(195 \pm$ 40.5 cells $/ \mu \mathrm{L}$ ) compared to counts for the non HIV-infected $(288 \pm 35.25 \mathrm{cells} / \mu \mathrm{L})$. In several studies of HIV infected patients with pulmonary TB, the median CD4 T-cell count was $<300$ cells $/ \mu \mathrm{L} .{ }^{17}$ Until 1993 , two clinical presentations of TB/HIV co-infection were recognized; TB in the HIVseropositive patients without AIDS and TB accompanied by AIDS. ${ }^{18}$ Subsequently, the World Health Organization classified TB as an AIDS defining condition in HIV infected patients. ${ }^{19}$ The CD4 lymphocyte count, which defines the degree of immunosuppression, is used to compare the clinical radiological presentations.$^{20}$ The CD4 lymphocyte count cut-off point has been defined as 200 cells $/ \mu \mathrm{L}$. Studies have shown that the primary progressive form of TB predominates in patients with CD4 counts $<200$ cells $/ \mu \mathrm{L} .{ }^{20}$ Although TB can be a relatively early manifestation of HIV-1 infection, it is important to note that the risk of developing $\mathrm{TB}$, and of disseminated infection, increases as the CD4 T-cell count decreases.

In this study, we observed a higher HIV prevalence rate among females $(80 \%)$ as compared to males $(20 \%)$. This higher incidence rate found within the women of this study parallels data observed in sub-Saharan Africa ${ }^{21}$ and of other parts of the world ${ }^{14}$ which estimated there were 12 to 13 infected women for every infected man. Biological, cultural and socio-economic factors contribute to women's greater vulnerability to HIV/AIDS. Women are four times more at risk of becoming infected with HIV during unprotected vaginal intercourse than men. The vagina's large surface area of susceptible tissue and micro trauma during intercourse makes women more physiologically vulnerable. ${ }^{22}$ The synergy between HIV and other sexually transmitted infections (STIs) is another biological factor that makes women more vulnerable. Socio economic factors including women's lack of access to education or personal income perpetuate women's lower status. Moreover widespread poverty drives some women into commercial sex work. Cultural traditions such as forced marriage, female genital mutilation and older men's preference for younger women contribute to the observed increased female vulnerability to HIV. ${ }^{23}$

A significantly high HIV prevalence rate was observed among subjects in the 28-37 and 38-47 year age groups followed by those less than 20 years. This is in agreement with previous reports ${ }^{11,12}$ which found the highest HIV seropositive rate among patients aged between 30 to 39 years $(10.6 \%)$. 
In this study we found HIV-1 as the predominant viral subtype responsible for HIV infection in TB infected patients in Port Harcourt, Nigeria. This finding is consistent with studies in other parts of Africa which found HIV-1 the predominant viral subtype. ${ }^{24-26}$ Never the less HIV-2 infection has been detected in other studies amongst African poulations. ${ }^{27,28}$

HIV prevalence was significantly higher among singles compared to married subjects. This finding is also consistent with previous reports ${ }^{29,30}$ which found single, unmarried persons more vulnerable to HIV infection. Single unmarried persons are more likely to maintain multiple sex partners or be involved in high risk sexual behaviors (homosexuality, commercial sex work, alcohol use and intravenous drug abuse) that make them vulnerable to infection with HIV. In the United States, a previous study has shown that people who use alcohol, tobacco, and other drugs are at a high risk for HIV infection. ${ }^{31}$ Both casual and chronic substance users are more likely to engage in high-risk behaviors such as unprotected sex, when they are under the influence of drugs or alcohol. ${ }^{32}$ Research conducted throughout sub-Saharan Africa has found close associations between alcohol use, risk taking sexual behavior, sexually transmitted infections and HIV infection. ${ }^{33}$

This study, has established the prevalence of human immunodeficiency virus infection among TB infected patients in Port Harcourt, Nigeria, and shows that a close link exists between active TB and HIV infection. We recommend that there be strict compliance to the Centers for Disease Control and Prevention (CDC) recommendation that all newly diagnosed TB patients be tested for HIV after counseling. Reactivation of TB among people living with HIV can be reduced by TB preventive therapy and by universal access to antiretroviral therapy.

\section{Acknowledgement}

We want to express our gratitude to all staff of the chest clinic Niger hospital, Port Harcourt and all the TB patients included in this study for their collaboration.

\section{References}

1. Blumberg HM, Burman WJ, Chaisson RE, et al. American Thoracic Society/Centers for Disease Control and Prevention/Infectious Diseases Society of America: treatment of TB. Am J Respir Crit Care Med. 2003; 167:603-662.

2. Low SY, Eng P. Human immunodeficiency virus testing in patients with newly-diagnosed TB in Singapore. Singapore Med Journal. 2009;50(5):479-481.

3. API consensus expert committee. API TB Consensus guidelines 2006. Management of pulmonary TB, extra-pulmonary TB and TB in special situations. J Assoc Physicians India. 2006;54:219-234.
4. Diagbouga S, Chazallon C, Kazatchkine MD, et al. Successful implementation of a low-cost method for the enumerating CD4 T-lymphocyte in resource limited setting: the ANRS 12-26 study. AIDS. 2003; 17:2201-2208.

5. Yusuph H. Prevalence of HIV infection, in TB patient in Nguru, North Eastern Nigeria. Sahel Medical Journal. 2005;8(3):65-67.

6. Eriki PP, Okwere A, Aisu T. The Influence of human immunodeficiency virus infection of TB in Kampala, Uganda. Annual Review of Respiratory Diseases. 1991;40:128-132.

7. Daniel OJ, Salako AA, Oluwole FA, Alausa OK, Oladapo OT. Human immunodeficiency virus sero-prevalence among newly diagnosed adult pulmonary TB patients in sagamu, Nigeria. Nigeria Journal of Medicine. 2004;3(4):393-397.

8. Elliott AM, Lout N, Tembo G, et al. Impact of Human immunodeficiency virus on TB patients in Zambia, a cross-sectional study. BMJ. 1990;301(6749):412-415.

9. Van Gorkan J, Kibuga D, Achallah Adungesi J, et al. Human immunodeficiency virus sero prevalence among TB patients in Kenya. East Africa Medical Journal. 1999;76(8):752-456.

10. Van Cleef MR, Chum HJ. The proportion of TB cases in Tanzania attributable to human immunodeficiency virus. Int J Epidemiol. 1995; 24(3):637-642.

11. De Cock KM, Soro B, Coulibaly IM, Lucas SB. TB and HIV infection in sub-Saharan Africa. JAMA. 1992;268:1581-1587.

12. Haar CH, Cobelens FGJ, Kalisvaart NA, Van der Have JJ, Van Gerven PJ, Van Deuteron H. HIV prevalence among TB patients in the Netherlands, 1993-2001: trends and risk factors. Int J Tuberc Lung Dis. 2006;10(7):768-774.

13. Markowitz N, Hansen NI, Hopewell PC, et al. Incidence of TB in the United States among HIV-infected persons. Ann Intern Med. 1997; 126:123-113.

14. Barnes PF, Bloch AB, Davidson PT, Snider DE Jr. TB in patients with human immunodeficiency virus infection. $N$ Engl J Med. 1991; 324(23):1644-1650.

15. Cantwell MF, Snider DE Jr, Cauthen GM, Onorato IM. Epidemiology of TB in the United States, 1985 through 1992. JAMA. 1994;272(7): 535-539.

16. Greenberg SD, Frager D, Suster B, Walker S, Stavropoulos C, Rothpearl A. Active pulmonary TB in patients with AIDS: spectrum of radiographic findings including a normal appearance. Radiology. 1994;193(1):115-119.

17. Geeta RG. How men's power over women fuels the HIV epidermic. Br Med J. 2002;423(7331):183-184.

18. Peter KL, Kriesten R, Willard C. HIV/AIDS evolving impact on global health. In: Ron Valdisern editior, Dawning answers. How the HIV/AID epidemic has strengthened public health. New York: Oxford Press; 2002.

19. Gomez AC, Marin VB. Gender, culture and power. Barriers to HIVprevention strategies for women. J of Sex Res. 1996;33(4):355-362.

20. Ramachandran R, Datta M, Subramani R, Baskaran G, Paramasivan CN, Suamenathan S. Sero prevalence of Human immunodeficiency virus infection among TB patients in Tamil Nadu. Ind J of Med Res. 2003; 118:147-151.

21. Brenan CA, Bodelle P, Coffey R, et al. The prevalence of diverse HIV-1 strains was stable in Cameroonian blood donors from 1996 to 2004. J Acquir Immune Defic Syndr. 2008;49(4):432-439.

22. Nyobi BM, Kristiansen KI, Bjune G, Muller F, Holm-Hansen C. Diversity of human immunodeficiency type 1 subtype in Kegera and Kilimanjaro regions, Tanzania. AIDS Res Hum Retroviruses. 2008; 24(6):761-769.

23. Pieniazek D, Ellenberger D, Janini LM, et al. Predominance of human immunodeficiency virus type 2 subtype in Abidjan, Ivory Coast. AIDS Res Hum Retroviruses. 1999;15(6):603-608.

24. Bonney EY, Sackey ST, Brandful JA. Laboratory diagnosis of dual HIV-1/HIV-2 infection in Ghanaian patients. East Afr Med J. 2008;85(11):537-543. 
25. Shiman R, Hui Y, Yanwen Z, et al. Rising HIV prevalence among married and unmarried among men who have sex with men: Jinan, China. AIDS and Behav. 2009;13(4):671-676.

26. Shisana O, Zungu-Dirwayi N, Toefy Y, Simbavi LC, Malik S, Zuma K. Marital status and risk of HIV infection in South Africa. S Afr Med J. 2004;94(7):537-543.

27. Murrill CS, Prevots DR, Miller MS, Linley LA, Royalty JE, Gwinn M. Incidence of HIV among injection drug users entering drug treatment programs in four US cities. J Urban Health. 2001;78(1):152-161.
28. Leigh BC, Stall R. Substance use and risky sexual behavior for exposure to HIV: issues in methodology, interpretation, and prevention. Am Psychol. 1993;48:1035-1045.

29. Kalichman SC, Simbavi LC, Kaufman M, Cain D, Jooste S. Alcohol use and sexual risks for HIV/AIDS in sub-Saharan Africa: systematic review of empirical findings. Prev Sci. 2007;8(2):141-151.

\section{Publish your work in this journal}

HIV/AIDS - Research and Palliative Care is an international, peerreviewed open-access journal focusing on advances in research in HIV, its clinical progression and management options including antiviral treatment, palliative care and public healthcare policies to contro viral spread. The journal welcomes original research, basic science, clinical \& epidemiological studies, reviews \& evaluations, expert opinion \& commentary, case reports \& extended reports. The manuscript management system is completely online and includes a very quick and fair peer-review system. Visit http://www.dovepress.com/ testimonials.php to read real quotes from published authors.

Submit your manuscript here: http://www.dovepress.com/hivaids---research-and-palliative-care-journal 